\title{
Rock Burst Danger Warning and Large Diameter Drilling Pressure-relief Technology in Fully Mechanized Caving Island Coal Face
}

GU Shitan ${ }^{1,2}$, XIAO Zhimin ${ }^{1,2}$, HUANG Ruifeng ${ }^{1,2}$, TAN Yunliang ${ }^{1,2}$, JIANG

$$
\text { Bangyou }^{1,2} \text {, LI Wenshuai }{ }^{1,2}
$$

(1. State Key Laboratory of Mining Disaster Prevention and Control Co-founded by Shandong Province and the Ministry of Science and Technology, Shandong University of Science and Technology, Qingdao 266590, China; 2. College of Mining and Safety Engineering, Shandong University of Science and Technology, Qingdao 266590, China)

\begin{abstract}
According to the appeared incident dynamic pressure of 1304 working face in a mine, the characteristics of electromagnetic emission signal were analyzed before the dynamic pressure occurred; FLAC3D was used to simulate the impact on pressure relief effect under the conditions of different borehole diameter, space and depths. The results showed that: electromagnetic emission intensity and pulse signals continual increase could be a symbol of shock hazard; the larger the borehole diameter, the smaller the borehole space, the greater the depth of the borehole, and the better relief; borehole depth must exceed
\end{abstract}

a certain range of stress concentration area, otherwise pressure relief effect was not obvious, and even increased the possibility of shock hazard. Based on the above findings, rock burst local prevention and control integration technology of "electromagnetic emission forecasting technology $\rightarrow$ drilling to determine the range of the risk $\rightarrow$ large-diameter borehole pressure relief technology $\rightarrow$ effects checking through electromagnetic emission" which was applied successfully was established.

Keywords: rock burst; electromagnetic emission; borehole pressure relief 


\section{Introduction}

Fully mechanized caving island coal face and surrounding roadway are at a state of high stress and the roof moves fiercely. With impact of geological structure, the rock burst occurs easily. Electromagnetic emission technology is an important method to monitor the rock burst. With the continuous progress of the mine monitoring equipment, the technology has been widely used in major mine[1-4]. Pressure relief is the ultimate point of rock burst monitoring and large-diameter pressure relief technology is common means. Many scholars and engineers had done lots of researches and made many achievements [5-8].

Most of relevant studies were for a single monitoring or control methods. In fact, there are many deficiencies to use a single access of monitoring to obtain premonitory information of rock burst. The single parameter warning is vulnerable to interference by unknown factors which will lead to misstatements and omissions because of the complexity of coal mine production system. And it will affect coal mining production safely and effectively.

Rock burst monitoring data was analyzed in 1304 island mining face to study the technology of electromagnetic emission monitoring, drilling to determine the range of the risk, large-diameter borehole pressure relief and effects check through electromagnetic emission which avoided the occurrence of rock burst disaster.

\section{General situation of engineering and geology}

The next section had been mined out in 1304 working face of mine. It was a typical both sides goaf of the island working face and belonged to C-shaped stope. The main coal seam was 3 coal. The depth was $573 \mathrm{~m}$ to $700 \mathrm{~m}$, plagioclase average was $184 \mathrm{~m}$, promoting length was $870 \mathrm{~m}$, dip angle was $17^{\circ}$ to $21^{\circ}$ and the average thickness of coal was $7.5 \mathrm{~m}$. Long wall fully mechanized top-caving techniques along strike was used for recovery and caving method was used in all the mined area. According to the measured of propensity of Coal Research Institute Beijing Institute of Mining Rock Mechanics Laboratory, the impact energy index in the upper and lower of 3 coal was 5.46, 2.86 and the elastic energy index was 5.32, 4.80. The determining was concluded as follows: the upper of 3 coal belonged to class III with strong impact tendency; the lower of 3 coal belonged to 
class II with weak impact tendency.

Table 1 Strong dynamic pressure

manifestation events of working face

Dynamic pressure show on

August 14

\begin{tabular}{cc}
\hline Time & $6: 35$ on August 14 \\
Location & $\begin{array}{c}\text { The tail entry from the coal wall } \\
\text { at the range of } 3-20 \mathrm{~m}\end{array}$ \\
& 4 props were broken and 13 props \\
wamage & were bent, floor heave of \\
& roadway appeared suddenly and \\
& the prop subsided $100-150 \mathrm{~mm}$. \\
\hline
\end{tabular}

Rock burst occurrence and abutment pressure distribution linked closely. Vertical stress distribution in C-type coal stope was shaped as "C" and abutment pressure peak was at deep down corners[9] of the working face. The upper and lower corners and rock of 1304 working face affected by high peak abutment pressure led to rock burst easily. The 1304 working face began mining on early July, 2012. The ground pressure was at a high level with strong dynamic and severely deformed along the groove in the process of mining. A dynamic pressure that occurred during mining face appeared was listed in Table 1.

\section{Electromagnetic emission}

\section{forecasting in the process of mining}

Fig.1 was statistical results of electromagnetic emission monitoring parameters on Aug 1 to Aug 13 in tail entry of 1304. It could be seen from Fig.1: Electromagnetic emission intensity and pulse signals were at highly downward trend and internal damage of coal-rock mass flattened with weak danger on Aug 1 to Aug 7. Then they increased constantly and the coal-rock mass tended to damage and fracture seriously on August 8 to August 10. It showed that the stress in this region was at a very high level; the electromagnetic emission intensity values and pulses declined on August 8-August 10 and increased after Aug 11. The pulses increased faster than the intensity values. The increasing of micro fracture frequency of coal-rock mass event showed that the energy accumulation in the region was at a very high level. Combined with Table 1, the dynamic pressure phenomenon occurred in working face on Aug 14. Therefore, when the electromagnetic emission intensity values and pulses were discovered to increase, the shock hazard should be alerted. Increasing of intensity values and pulses could be seen as warning conditions. The electromagnetic emission forecasting should be carried out prior to Aug 13, and pressure relief should be carried out to get rid of danger. 
Electromagnetic emission intensity and pulse signals were indicators of internal energy releasing of coal-rock mass. Before dynamic pressure occurred, coal-rock mass constantly tended to damage and fracture seriously, and the energy releasing continued to strengthen. When the release rate of energy was slower than the rate of accumulation, the coal-rock mass could not maintain static equilibrium, and the energy would be released in the form of dynamic and the rock burst would happen.

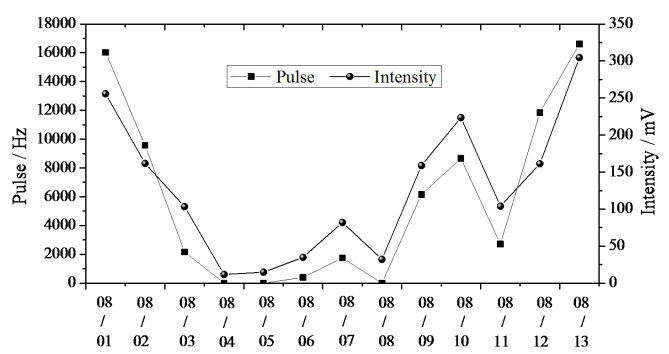

Fig.1 Data statistics of electromagnetic emission between Aug. 1 to Aug.13

4. Large-diameter borehole pressure relief technology and application in rock burst dangerous zone

4.1 Pressure relief effects with different drilling parameters

\section{1) Establishment of the numerical model}

In order to study the unloading mechanism of large-diameter borehole, the influences of various factors on the effect of unloading were considered as much as possible. Influences of borehole diameter, space and depth on the effect of unloading were studied by FLAC3D numerical test. Then 9 numerical models were set up. The front, back, left and right of model were fixed by horizontal restriction, and the bottom of the model was fixed by vertical restriction. While, the equivalent load $(\mathrm{P}=\gamma \cdot \mathrm{h})$ was applied on vertical orientation of the upper boundary of model to simulate weight of overlying strata. And the $\gamma$ was taken $25 \mathrm{kN} / \mathrm{m}^{3}$ which showed the average unit weight of overlying strata, $h$ showed the average distance of upper model to the earth surface. The Mohr-Coulomb yield criterion was used in the process of simulation, the physical and mechanical parameters were listed in table 2 . 
Table 2 Parameters of model

\begin{tabular}{ccccccc}
\hline $\begin{array}{c}\text { Lithological } \\
\text { characters }\end{array}$ & $\begin{array}{c}\text { Bulk modulus } \\
\text { (GPa }\end{array}$ & $\begin{array}{c}\text { Shear modulus } \\
/ \mathrm{GPa}\end{array}$ & $\begin{array}{c}\text { Cohesion } \\
/ \mathrm{MPa}\end{array}$ & $\begin{array}{c}\text { Friction angle } \\
/\left({ }^{\circ}\right)\end{array}$ & $\begin{array}{c}\text { Tension strength } \\
/ \mathrm{MPa}\end{array}$ & $\begin{array}{c}\text { Density } \\
\rho /\left(\mathrm{kg} \cdot \mathrm{m}^{-3}\right)\end{array}$ \\
\hline $\begin{array}{c}\text { Middle-fine } \\
\text { sandstone }\end{array}$ & 20 & 11 & 8.3 & 37 & 4.9 & 2750 \\
Siltstone & 15.6 & 10.8 & 7.2 & 44 & 5.0 & 2800 \\
Coal seam & 2.9 & 1.65 & 2.2 & 22 & 0.9 & 1480 \\
Siltstone & 15.6 & 10.8 & 7.2 & 44 & 5.0 & 2800 \\
Fine sandstone & 23 & 12 & 7.5 & 32 & 2.2 & 2700
\end{tabular}

Table 2 Parameters of model Fig.3 Szz contour map with 100mm borehole

\section{2) Influence of drilling diameter on}

\section{pressure relief effect}

The borehole space was $3 \mathrm{~m}$ and depth was $20 \mathrm{~m}$, and mining depth was $800 \mathrm{~m}$, the influence of diameter of borehole on the effect of pressure relief was analyzed by taking different borehole diameter, such as $50 \mathrm{~mm}, 100 \mathrm{~mm}$ and $200 \mathrm{~mm}$. Stress contour maps of SZZ under different borehole diameters were shown in Fig.2 to Fig.4.

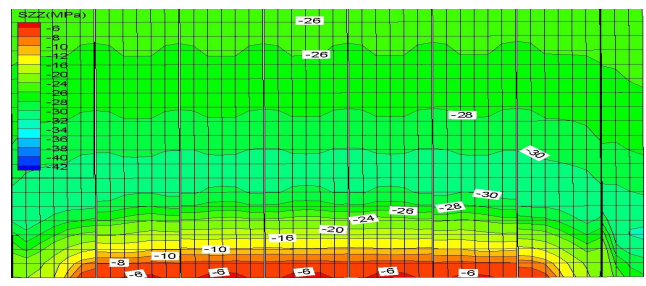

Fig.2 Szz contour map with 50mm borehole diameter

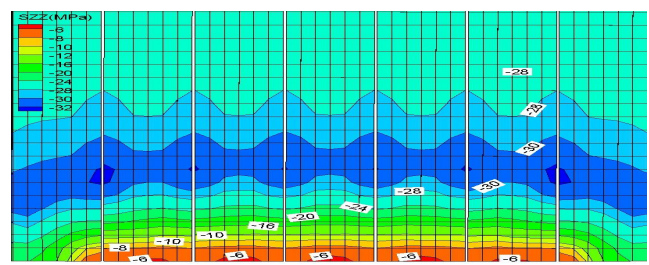

\section{diameter}

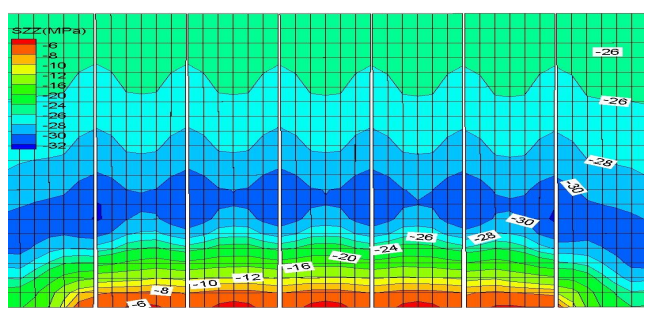

Fig.4 Szz contour map with $200 \mathrm{~mm}$ borehole diameter

Follow views could be obtained from Fig.2 to Fig.4. (1)With the borehole unloading, stress around the borehole was redistributed, the area of stress concentration transferred to the deep. And the stress took the borehole as the center and extended regularly to both sides. The larger the borehole diameter, the wider of stress-relaxed range, and the more obvious of the unloading effect. (2) The larger the borehole diameter, the smaller the stress-concentrated area, and the better unloading effect. Then the possibility of rock burst occurrence was lower. 


\section{3) Pressure relief effects in different}

\section{borehole space}

Taking borehole diameter for $100 \mathrm{~mm}$ and depth for $20 \mathrm{~m}$, and mining depth for $800 \mathrm{~m}$ unchanged, pressure relief effect in different borehole space was studied by analyzing different borehole space such as $1 \mathrm{~m}, 3 \mathrm{~m}$ and $5 \mathrm{~m}$. Fig. 5 to Fig. 7 showed the maximum principal stress contour maps with different drilling space.

Follow conclusions could be gained from Fig.5 to Fig.7. (1) Maximum main stress of coal seam was reduced from $20 \mathrm{MPa}$ to $6 \mathrm{MPa}$ around borehole in which formed remarkable stress-relaxed district. (2) When borehole space was $1 \mathrm{~m}$, the stress-relaxed area connected entirely. In other words, pressure relief district was continuous and closed, which showed remarkable pressure relief effect. Then, with drilling space increasing, the stress-relaxed district gradually lost continuity, and formed mutual independent non-continuous region, pressure relief effect constantly became poorly.

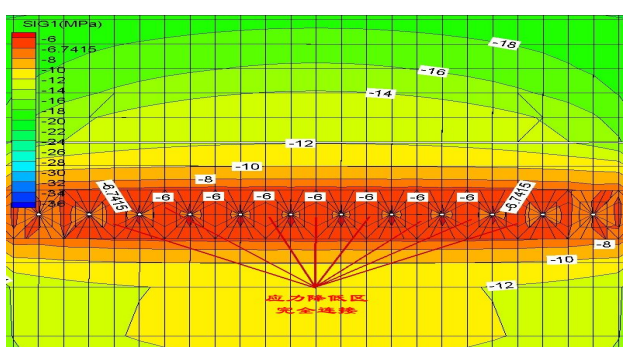

Fig.5 Maximum principle stress contour map with $1 \mathrm{~m}$ between boreholes

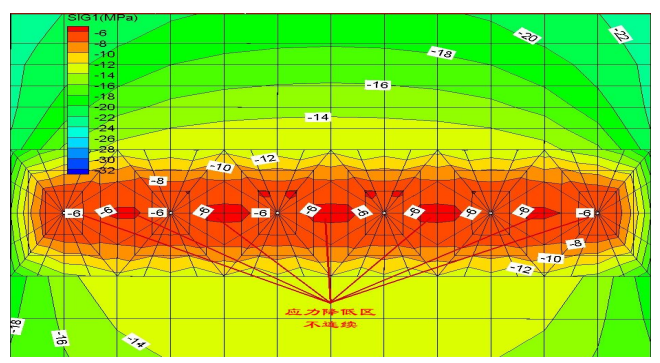

Fig.6 Maximum principle stress contour map with $3 \mathrm{~m}$ between boreholes

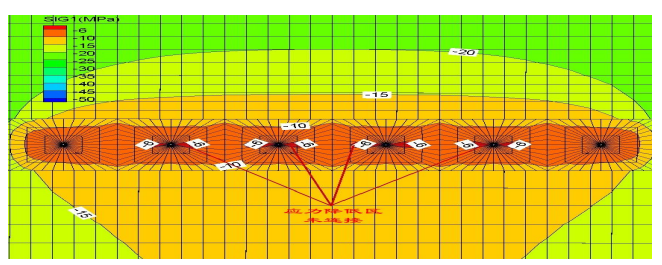

Fig.7 Maximum principle stress contour map with $5 \mathrm{~m}$ between boreholes

\section{4) Pressure relief effect influenced by drilling depth}

Presetting borehole space to $3 \mathrm{~m}$, diameter to $100 \mathrm{~mm}$ and mining depth to $800 \mathrm{~m}$, area of stress concentration was created by excavating chamber with length of $8 \mathrm{~m}$, width of $6 \mathrm{~m}$ and height of $3 \mathrm{~m}$ in both sides of model. Then coal pillar width was $20 \mathrm{~m}$. Boreholes of $5 \mathrm{~m}, 15 \mathrm{~m}$ and $20 \mathrm{~m}$ were excavated from chamber to coal seam, pressure relief effects under 
different borehole depth were researched, which was in same stress concentrated degree. Energy difference before and after borehole could be used to express pressure relief effect. Energy difference could be interpreted as difference of accumulated energy and released energy of brittle failure of rock mass. Fig.8 showed energy difference curve between the before and after unloading.

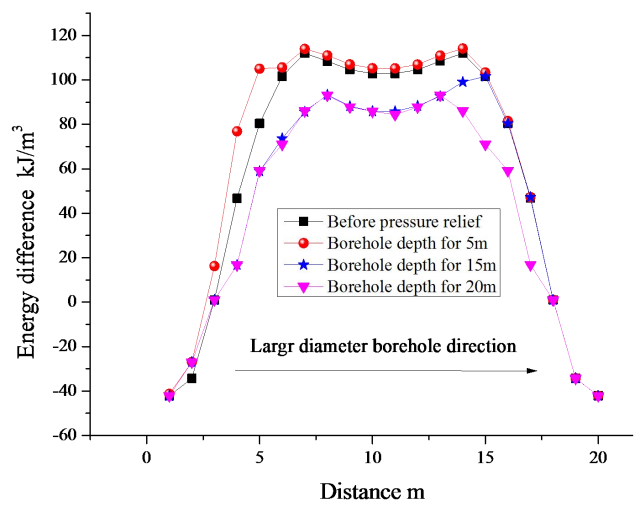

Fig.8 Curves of pressure relief effect with different drilling depth

Follow views could be obtained from Fig.8. (1) The peak of Energy difference was located in front of rib about $7 \mathrm{~m}$. (2) When borehole was $5 \mathrm{~m}$-depth, the effect of pressure relief was poor. This phenomenon could be accounted for the drilling depth which was too short to reach the stress concentration area. And not only can not achieve pressure relief effect, but actually increasing dangerous of rock burst. (3) Energy difference value along borehole axis reduced obviously, at the same time, the peak value was shift to the deep. However, the effect on pressure relief limits at about $15 \mathrm{~m}$. (4) Pressure relief effect was extremely well with borehole depth for $20 \mathrm{~m}$, and rock burst danger was greatly reduced.

\section{5) Comprehensive analysis of reasonable pressure relief borehole parameters}

Drilling parameters, stress concentration degree and range of working face, coal-rock mass mechanical properties and other factors are closely relevant to the success of borehole pressure relief. Generally, the larger diameter and depth of the borehole, the smaller of bore space, and the greater effect of pressure relief. Borehole depth must exceed certain limits of stress concentration area, otherwise effect of pressure relief is not obvious, and the risks of rock burst may even increase. It is important to note that borehole parameters should be determined in many ways in field. Moreover, the pressure relief effect should be tested to determine the feasibility of parameter.

\subsection{Utilize of large diameter borehole pressure relief technology}

Fig.9 was electromagnetic emission data statistical figure of 1304 working face 
transportation roadway which advanced $10 \mathrm{~m}$ to $30 \mathrm{~m}$. As was seen from figure 9 , both the entity coal wall electromagnetic emission intensity and pulse count in the transportation roadway continued to rise from September 23 to October 2, and had a great increase, which met the dangerous warning condition of rock burst. Analytically, the coal wall in the transportation roadway which advanced $10 \mathrm{~m}$ to $30 \mathrm{~m}$ was warned on October 2 . In addition, the method of drilling cuttings was used to identify the precise region of rock burst. As a result, $15 \mathrm{~m}$ to $25 \mathrm{~m}$ in front of working face determined the dangerous area of rock burst.

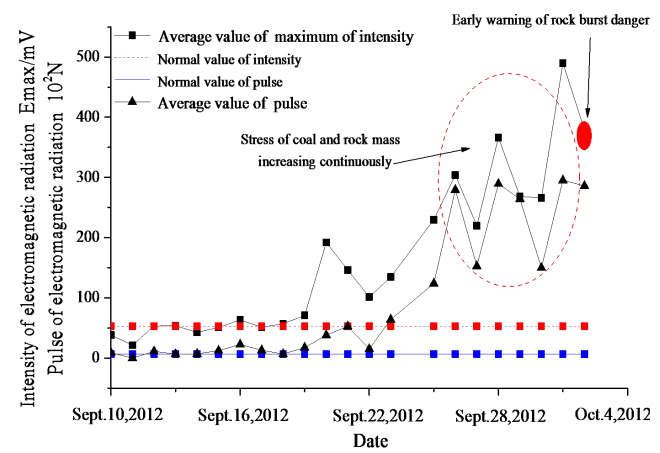

Fig.9 Law of electromagnetic emission signal when advanced $10 \mathrm{~m}$ to $30 \mathrm{~m}$ of working face Large diameter drilling pressure relief technology was used to release the accumulation of elastic strain energy in the area of stress concentration in transportation roadway, which reduced the stress concentration of coal wall, and prompted the abutment pressure peak transferring to the depth of the coal. Then the purpose of decreasing risk of rock burst could be reduced.

\section{1) Construction method}

Taking Hydraulic safety drill on pressure relief boreholes, the operating floor was no less than drilling machine $5 \mathrm{~m}$. Before drilling pressure relief boreholes, the range, condition and criticality should be checked out. Pressure relief boreholes should be started from low stress area to high stress area. At the same time, the drilling cutting quantity, dynamic phenomenon and special circumstances per meter was recorded.

\section{2) Arrangement of boreholes}

Pressure relief borehole diameter was $110 \mathrm{~mm}$, and was arranged in central of height of roadway. In addition, depth of it should be achieved to high stress concentration zone, which was taken for $25 \mathrm{~m}$ in the field and space of borehole was taken for $3 \mathrm{~m}$.

\section{3) Pressure relief effect test of working face}

The large-diameter borehole pressure relief was conducted in warning area on October 2. In that case, the advanced abutment pressure peak was transferred to the deep. And value of strength and 
pulse of electromagnetic emission of the coal was dropped under the normal levels, which could be seen from Fig.10. This phenomenon indicated that the risk of rock burst was decreased and warning could be relieved.

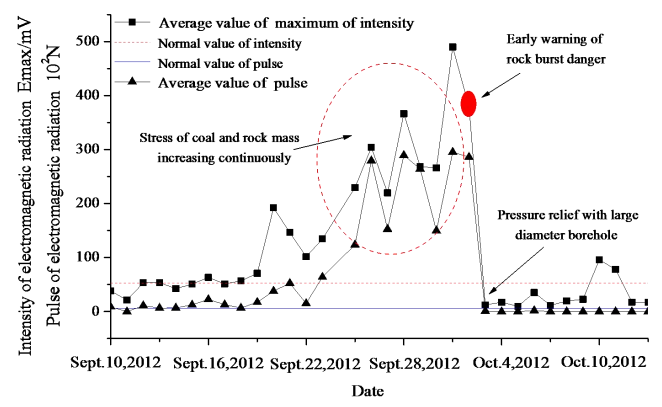

Fig.10 Electromagnetic emission signal variation

\section{Conclusions}

Theoretical analysis, numerical simulation and field test methods were used to study danger rescission technology of rock burst in fully mechanized top-coal caving face. The main conclusions were showed as follows:

(1) Before dynamic pressure occurred, coal-rock mass constantly tended to damage and fracture seriously, and the energy releasing continued to strengthen. Electromagnetic emission signals highly increased with anomalies. When the releasing rate of energy was slower than the rate of accumulation, the coal-rock mass could not maintain static equilibrium, the energy would be released in the form of dynamic and the rock burst would happen.

(2) $\mathrm{FLAC}^{3 \mathrm{D}}$ and orthogonal test were used to study the impact pressure relief effect under the conditions of different borehole diameter, space and depths. The results showed that the larger the borehole diameter, the smaller space and the greater depth of hole, and the better relief; the depth of borehole must exceed a certain range of stress concentration area, otherwise relief effect was not obvious, and even increased the chance of rock burst.

(3) Rock burst local prevention and control integration technology of "electromagnetic emission forecasting technology $\rightarrow$ drilling to determine the range of the risk $\rightarrow$ large-diameter borehole pressure relief technology $\rightarrow$ effects checking through electromagnetic emission" which prevented the occurrence of rock burst ensured the working face mining safely and effectively in the process of coal mining.

\section{Acknowledgments}

This work is financially supported by National Natural Science Foundation of China (No.51374140 ; No.51204102).

\section{References}


[1] SU Weijia, QI Hongtao, SU Chang. Experiment on changing of surface charge during load-bearing process of $\operatorname{rock}[\mathrm{J}]$. Journal of Liaoning Technical University (Natural Science Edition), 2013， 32(12): 1651-1654.

[2] Frid V, Vozoff K. Electromagnetic emission induced by mining rock failure $[\mathrm{J}]$. International Journal of Coal Geology, 2005, 64(1-2): 57-65.

[3] SA Zhanyou. Study on the EME effects and anomaly judging technologies during the rheological fracture of coal or rock[D]. Xuzhou: China University of Mining and Technology, 2003.

[4] LI Hong, JIANG Jinquan. Predicting Study on rock burst according to electromagnetic emission through pattern recognition with the help of multi-features[J]. Chinese Journal of Rock Mechanics and Engineering, 2006, 25(supp.2): 3775-3781.

[5] LI Guohong, YANG Fawu, WU Yuanliang. Practice of rock burst prevention and control with pressure relief borehole[J]. Coal Mine Safety, 2004, 35(11): 8-10.

[6] LAN Yongwei, ZHANG Yongji, GAO Hongmei. Study of release pressure boring with numerical simulation[J]. Journal of Liaoning Technical University, 2005, 24(Supp1): 275-277.

[7] WEN Yingyuan, MU Zonglong, CAI $\mathrm{Wu}$, et al. The parameter optimization analysis of borehole pressure relief in coal seam based on orthogonal test $[\mathrm{J}]$. Coal Mine Safety, 2013, 44(5): 170-173.

[8] LI Jinkui, XIONG Zhenhua, LIU Dongsheng, et al. Numeric simulation od borehole pressure relief preventing roadway rock burst of a mine[J]. Journal of Xi'an University of science and technology, 2009, 29(4): 424-426.

[9] LIU Jinhai, JIANG Fuxing, FENG Tao. Numerical simulation of abutment pressure distribution of C-shaped stope $[\mathrm{J}]$. Rock and Soil Mechanics, 2010, 31(12): 4011-4015. 